Revista de la red interuniversitaria de estudios sobre las literaturas rioplatenses contemporáneas en Francia

$8 \mid 2013$

Argentina y Uruguay: lecturas del país vecino en la literatura rioplatense contemporánea (siglos XX y XXI)

\title{
Buscando la obra. Juan José Saer, Papeles de trabajo. Borradores inéditos
}

\section{Carlos Walker}

\section{OpenEdition}

\section{Journals}

Edición electrónica

URL: http://journals.openedition.org/lirico/932

DOI: $10.4000 /$ lirico.932

ISSN: 2262-8339

Editor

Réseau interuniversitaire d'étude des littératures contemporaines du Río de la Plata

\section{Referencia electrónica}

Carlos Walker, « Buscando la obra. Juan José Saer, Papeles de trabajo. Borradores inéditos », Cuadernos LIRICO [En línea], 8 | 2013, Publicado el 01 enero 2013, consultado el 22 septiembre 2020. URL : http:// journals.openedition.org/lirico/932; DOI : https://doi.org/10.4000/lirico.932

Este documento fue generado automáticamente el 22 septiembre 2020

\section{(c) (i) () $\Theta$}

Cuadernos LIRICO está distribuido bajo una Licencia Creative Commons Atribución-NoComercialSinDerivar 4.0 Internacional. 


\title{
Buscando la obra. Juan José Saer, Papeles de trabajo. Borradores inéditos
}

\author{
Carlos Walker
}

REFERENCIA

Juan José Saer. Papeles de trabajo. Borradores inéditos, Buenos Aires, Seix Barral, 2012, $388 \mathrm{p}$. 
1 En unas breves reflexiones sobre las relaciones entre la literatura y la política, Juan José Saer, de veintitrés o veinticuatro años, con un solo libro publicado en su haber, escribe en uno de sus cuadernos lo siguiente: "Esto también hay que decirlo de una vez por todas : no hay compromiso fuera de la obra." (104). Esta afirmación leída hoy, luego de publicados todos los libros que proyectó y trabajó el autor, sorprende por la temprana convicción del escritor, y por la manera en que esa frase va tomando forma en los libros que la suceden. Por otra parte, y si se deja de lado la sorpresa inicial, la frase citada señala un horizonte en el que los Papeles de trabajo pueden ser leídos. Así, más allá de la evidente finitud que marcan las ediciones de los libros preparados por Saer, Papeles plantea, otra vez, la cuestión

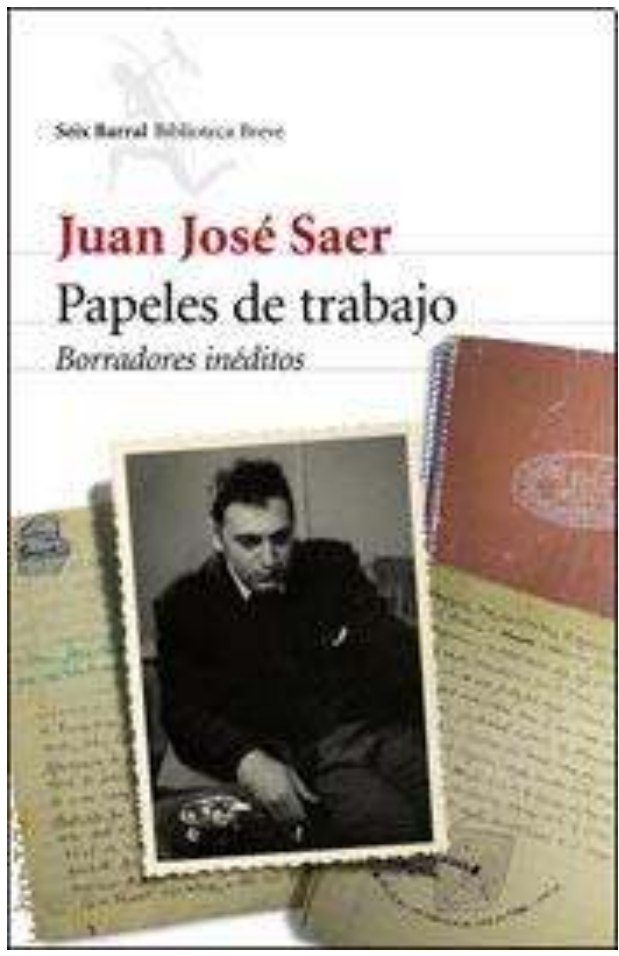
del presente de la obra y la posibilidad de seguir leyéndola en contra de la cristalización que pareciera reclamar la canonización del autor. Es posible plantear así preguntas tentativas: ¿qué lecturas de la obra se hacen posibles luego del acontecimiento que implica esta nueva publicación ? o bien : ¿cómo se altera el conjunto ya conocido a partir de la edición de estos cuadernos? Enunciar estos interrogantes es un modo de subrayar la permanente puesta en tensión de la forma que tiene lugar en la escritura de Saer, e indicar así la posibilidad de leer Papeles menos como un rejunte de anécdotas de lo que no llegó a los libros, que como fragmentos heterogéneos de una obra que a cada paso delinea su compromiso. ${ }^{1}$

Quizá una de las características más destacables, y que atraviesa las distintas facetas que se dan cita en este libro, sea la formación de un pensamiento literario que desde sus comienzos se propone como la puesta en marcha de un proyecto estético. Los diversos tipos de anotaciones de Saer responden a una reflexión y extensión permanente de la forma literaria. Se trata de un ejercicio de búsqueda de la obra, y de su superposición con lo que en ese movimiento llega a los libros publicados. Una contradicción se pone así en evidencia : la obra importa en la medida que posibilita su propia búsqueda, y es esa inclinación a la que se asiste a través de la lectura de estos cuadernos $^{2}$.

3 La edición de Papeles llega luego de cinco años de trabajo por parte de un grupo de investigadores dirigido por Julio Premat, quienes organizaron y transcribieron el material encontrado en gran parte en el armario del escritor: sesenta cuadernos, veinte carpetas y hojas sueltas. El texto introductorio de Premat explica la manera en que se ordenaron estos papeles, esgrime una clasificación de los escritos a partir del tipo de relación que establecen con el trabajo de escritura, distingue tres períodos diferentes según el tipo de escritura y su datación, desarrolla hipótesis de lectura sobre el lugar de los borradores en relación con la obra édita, y anuncia el contenido de los tres 
volúmenes que restan por publicar (un segundo tomo de Papeles de trabajo, un volumen de poesía y otro de ensayos).

El libro está compuesto de ocho cuadernos numerados del cero al siete, más el denominado "Cuaderno núcleo" y los "Documentos y variantes de La ocasión". Los textos están fechados desde antes de 1960 hasta 1987. Los primeros siete cuadernos son parte de un período más acotado (aproximadamente desde 1960 hasta 1967), y permiten leer las notas de Saer en sus comienzos. En el resto del material el marco temporal es más extenso. Hay cuadernos que, sea porque fueron interrumpidos y retomados, sea porque hacen las veces de lugar de reunión de textos e ideas transversales a la puesta en forma del proyecto literario, acompañan el trabajo de la obra por varios años. El caso más notable es el "Cuaderno núcleo", que abarca un marco temporal que va de 1963 a 1978. Allí se encuentran notas de lectura, proyectos truncos de relatos y novelas, aforismos, haikus, diversas reflexiones sobre literatura, poemas, y un largo etcétera de anotaciones que, en diálogo permanente con la obra, confirman la importancia de estos escritos en el andamiaje del proyecto saereano. Al final del libro se incluyen a modo de apéndice anotaciones sobre las características de cada cuaderno (dónde se encontró, la marca, el número de páginas, etc.), sobre el criterio de selección del material incluido en esta publicación, y notas que señalan relaciones, variaciones y lecturas en conjunción con la obra édita de Saer.

Dentro de las decisiones editoriales explicadas en la "Introducción general", se destaca la división establecida entre, por un lado, lo que en términos generales fue excluido, es decir "las notas preparatorias y los manuscritos de los libros editados" (9), y por otro, los elementos heterogéneos a partir de los cuales se conformó Papeles. Esta delimitación, si bien flexible, constituye una de las hipótesis de trabajo enunciadas por Premat en el prólogo, a saber, concebir la colección de textos que este libro presenta como "borradores de toda la obra, no manuscritos de los libros publicados" (22); por otra parte, deja abierto el espacio para futuros trabajos editoriales y críticos sobre los cuadernos que se relacionan de forma directa con la obra édita. ${ }^{3} \mathrm{Al}$ respecto merecen una mención especial los tres tanteos de comienzo de El limonero real que forman parte del "Cuaderno 2". En primer lugar, es dable subrayar que dicha novela ya se estaba escribiendo en 1964 (diez años antes de su publicación), bajo los títulos "Los limones bajo la luna" y "La mañana sobre el planeta". Uno de estos comienzos está narrado en primera persona, y lleva a imaginar, vanamente por cierto, qué habría sido de esa novela de ser Wenceslao el narrador. En segundo lugar, cabe la referencia a lo descrito en las "Notas" finales sobre la forma de composición de esta novela, pues se trataría de un caso único en el trabajo de escritura del santafesino. Esto porque tanto la alteración del orden de episodios como la reestructuración del conjunto, e incluso la existencia de un borrador muy diferente de la versión final -procedimientos ausentes del resto de las narraciones publicadas-, hacen pensar en un trabajo de montaje. Esta característica sugiere una manera diversa y desconocida del modo de escritura de Saer, vislumbrado con anterioridad en la edición crítica y genética de Glosa y El entenado ${ }^{4}$, e indica así la posibilidad de un trabajo genético que aborde el momento fuertemente experimental que representa El limonero real dentro de la obra, en conjunción con los movimientos de montaje y desmontaje que le habrían dado forma. La edición de Papeles entonces, no sólo hace visibles los borradores de toda la obra, sino que a la vez advierte sobre la existencia de borradores de la obra édita que aguardan renovados esfuerzos críticos. 
6 La publicación del primer tomo de los Papeles de trabajo de Saer permite señalar grosso modo dos cuestiones : por un lado, ofrece la posibilidad, ya entrevista en la edición de Colección Archivos, de adentrarse en los modos de trabajo del escritor. Imaginar y reconstruir las formas que tomó la obra de Saer desde sus comienzos es quizá uno de los asuntos más visibles de esta nueva publicación. En segundo lugar, y en estrecha relación con lo anterior, las modalidades de trabajo que se hacen visibles en estas páginas permiten volver a la obra édita y generar hipótesis de lectura que integren este material, haciendo así efectivo el diálogo permanente que aquí se evidencia entre el lugar de estos cuadernos y el de los textos publicados.

7 Esta relación se puede ver por ejemplo en un relato titulado "La habitación de la luz", incluido en el "Cuaderno 6" y fechado en 1966. Allí un joven Carlos Tomatis recibe de improviso la visita de una vieja actriz y su acompañante, quienes precisan dos cosas de él : que averigüe el lugar exacto de la ciudad en que Higinio Gómez se suicidó, y que luego escriba y publique en La región una nota sobre la obra del tal Higinio, de quien Tomatis, hasta ese día, no había siquiera escuchado hablar. El relato, que incluye varios protagonistas habituales de la narrativa saereana como Adelina Flores, Barco y Leto, podría ser un primer momento cronológico de los acontecimientos narrados en "Biografía de Higinio Gómez", un texto que integrará luego La mayor y en el que Tomatis ya escribió una plaqueta comentando la obra de Higinio. El texto de "Argumentos" también revela que la gran carpeta negra cargada por el amigo de la actriz en Papeles contiene los manuscritos de Higinio que serán luego entregados a Tomatis para la confección de esa plaqueta. El suicidio de Higinio encuentra una variación en "El fin de Higinio Gómez", incluido en El arte de narrar. Allí Tomatis, conocido de Higinio, da cuenta de los pormenores de dicha muerte y del entierro que dada la ausencia de familiares tuvieron que costear entre los pocos asistentes. Este tipo de relación entre los cuadernos y lo que luego formará parte de los libros da cuenta de un diálogo silencioso que en ese desplazamiento tiene lugar: un ir y venir que es al mismo tiempo modalidad de trabajo y concepción de la literatura. Tal como sugiere Premat en la edición Archivos, la obra se constituye a partir de expansiones y variaciones de lo ya escrito.

8 Entre los variados fragmentos que componen el libro, se puede subrayar una pregunta que insiste desde distintos ángulos. Se trata de la importancia que en las diversas entradas adquiere la relación entre literatura y experiencia. Este motivo de reflexión y creación permanente dirige la atención de Saer hacia la experimentación formal que sería propia de lo literario. Así, por ejemplo, junto a la declarada intención de oponer misticismo y literatura $(211,293)$, y a una suerte de metodología que concibe al novelista en términos de un sujeto que simultáneamente es observador $\mathrm{y}$ experimentador (244), Saer propone una concepción del “artista como crítico" centrada en la propia experiencia creadora (299). Ahora bien, como era de suponerse ese lugar destacado de lo experimental se manifiesta negativamente: “...la expresión poética debe ser el resultado de un descarte minucioso de nuestra experiencia, hasta conservar solamente aquella porción de la misma que aporte un elemento nuevo." (268). La negatividad conjuga experiencia y experimentación formal ; así la literatura de Saer busca y crea sus propios criterios de crecimiento.

9 La lectura de los Papeles de trabajo invita a releer la obra de de Saer no para perseguir con entusiasmo los defectos de composición que el contraste entre lo editado y los cuadernos podría propiciar, ni para sortear la brecha evidente que hay entre la obra 
édita y sus borradores, sino más bien para evidenciar la fidelidad a una visión de la literatura que encuentra en estos cuadernos una versión renovada.

\section{NOTAS}

1. Es pertinente recordar aquí un modo en el que Saer pensaba los fragmentos en relación a las formas literarias: "El fragmento no posee la autonomía de un género, sino que depende, para existir como fragmento, de su relación con una intención totalizadora, explícita o implícita. El fragmento existe como texto conflictivo, como residuo de una praxis problemática." (Saer por Saer, 1986 : 15).

2. Tal contradicción ha sido señalada por Maurice Blanchot a propósito de las complejas relaciones que tienen lugar entre literatura, obra y experiencia. Cito un breve fragmento donde se subraya esta tensión: "Les œuvres devraient donc jouer le plus grand rôle. Mais en est-il ainsi? Nullement. Ce qui attire l'écrivain, ce qui ébranle l'artiste, ce n'est pas directement l'œuvre, c'est sa recherche, le mouvement qui y conduit, c'est l'approche de ce qui rend l'œuvre possible : l'art, la littérature et ce que dissimulent ces deux mots." (Le livre à venir, 2008 : 270-271). 3. Disponible en la Universidad de Princeton : Juan José Saer Manuscripts, código C1393 (14 cajas). Catálogo consultable en http://findingaids.princeton.edu/

4. Juan José Saer, Glosa - El entenado, edición crítica coordinada por Julio Premat, colección Archivos, Córdoba, Alción, 2010.

\section{AUTORES}

\section{CARLOS WALKER}

Université de Liège (Bélgica)- Cofund 